medRxiv preprint doi: https://doi.org/10.1101/2020.03.24.20042762; this version posted March 26, 2020. The copyright holder for this preprint (which was not certified by peer review) is the author/funder, who has granted medRxiv a license to display the preprint in perpetuity.

It is made available under a CC-BY-NC-ND 4.0 International license .

\title{
A model to estimate bed demand for COVID-19 related hospitalization
}

Teng Zhang, BS ${ }^{1+}$, Kelly McFarlane, $\mathrm{BS}^{2,3+}$, Jacqueline Vallon, BS BA ${ }^{1+}$, Linying Yang, $\mathrm{BS}^{4}$, Jin Xie, $\mathrm{BS}^{4}$, Jose Blanchet, $\mathrm{PhD}^{1}$, Peter Glynn, $\mathrm{PhD}^{1}$, Kristan Staudenmayer, MD MS ${ }^{5}$, Kevin Schulman, $\mathrm{MD}^{6,7^{*}}$, and David Scheinker, $\mathrm{PhD}^{1,7-9 *}$

${ }^{1}$ Department of Management Science and Engineering, Stanford University School of Engineering, Stanford, CA

${ }^{2}$ Stanford Graduate School of Business, Stanford, CA

${ }^{3}$ Harvard Medical School, Boston, MA

${ }^{4}$ Institute for Computational \& Mathematical Engineering, Stanford University School of Engineering, Stanford, CA

${ }^{5}$ Department of Surgery, Stanford University School of Medicine, Stanford, CA

${ }^{6}$ Department of Medicine, Stanford University School of Medicine, Stanford, CA

${ }^{7}$ Clinical Excellence Research Center, Stanford University School of Medicine, Stanford, CA

${ }^{8}$ Department of Pediatrics, Stanford University School of Medicine, Stanford, CA

${ }^{9}$ Department of Perioperative Services, Lucile Packard Children's Hospital, Stanford, CA

${ }^{+}$These authors served as co-first authors

*These authors served as co-senior authors

Corresponding Author:

David Scheinker, PhD

Department of Management Science and Engineering

475 Via Ortega

Stanford, CA 94305-4121

dscheink@stanford.edu

650-683-5623

Word Count: 1143

Key words: COVID-19, model, bed demand, hospitalization, ICU

Figures: 1

Tables: 1

NOTE: This preprint reports new research that has not been certified by peer review and should not be used to guide clinical practice. 1 
As of March 23, 2020 there have been over 354,000 confirmed cases of coronavirus disease 2019 (COVID-19) in over 180 countries, the World Health Organization characterized COVID-19 as a pandemic, and the United States (US) announced a national state of emergency. ${ }^{1,2,3}$ In parts of China and Italy the demand for intensive care (IC) beds was higher than the number of available beds. ${ }^{4,5}$ The limited availability of testing results in the US make it challenging to estimate the demand for hospital beds that will be generated by COVID-19 patients. We sought to build an accessible interactive model that could facilitate hospital capacity planning in the presence of significant uncertainty about the proportion of the population that is COVID-19+ and the rate at which COVID-19 is spreading in the population. Our approach was to design a tool with parameters that hospital leaders could adjust to reflect their local data and easily modify to conduct sensitivity analyses.

We developed a model to facilitate hospital planning with estimates of the number of Intensive Care (IC) beds, Acute Care (AC) beds, and ventilators necessary to accommodate patients who require hospitalization for COVID19 and how these compare to the available resources. We deployed this model as an interactive online tool. ${ }^{6}$

Inputs to the model include estimates of the characteristics of the patient population and hospital capacity. The patient population inputs are the starting population of COVID-19- patients, COVID-19+ patients, and the estimated doubling time for total COVID-19 admissions (i.e. how many days it will take for the number of total admissions at the institution to double). For the patient cohorts, we estimated what percentage of the COVID-19+ patient population would follow 5 potential trajectories through the hospital, assuming various combinations of patient flow between IC and AC. Until more reliable data are available, estimates for input values are generated through review of existing data and discussion with experts. ${ }^{7,8}$ The model will be updated as data become available.

The model produces a daily time series. The first day of the simulation (Day 0 ) is fixed. For each subsequent day the model uses the projected number of COVID-19 patients, partitions the patients into cohorts, and updates the number of COVID-19 patients requiring IC and AC beds as follows:

1. COVID-19 Admissions: We project the total COVID-19 admissions with an exponential growth model using data based on the first 14 days of patient admissions (The number of total admitted patients up to day $\mathrm{n}$ is the product of the number of patients admitted up to day 0 and 2 to the power of $\mathrm{n}$ divided by the doubling time).

2. Patient Cohorting: The patients are partitioned into 5 care cohorts: Cohorts 1 and 5 are patients who spend time only on, respectively, a General Medicine AC floor and an IC unit. The remaining 3 cohorts are patients who spend time in an IC unit, only before, only after, or both before and after spending time on an AC unit (Table 1).

3. Cohort Length of Stay: Each patient in each cohort spends the number of days specified by the parameter inputs in the IC and AC units. The total census in each of the IC and AC units for each day is calculated as the sum of the patients that arrived in that unit minus the sum of the patients that have been discharged from that unit.

4. Projected IC Bed Requirements: The number of IC beds required each day is the sum of the number of COVID-19+ and COVID-19- IC patients.

5. Projected COVID-19 Medical Team Requirements: The number of patients to be cared for by the Medical Service each day is the sum of the number of COVID-19+ AC patients and COVID-19- patients being cared for by the Medicine Service.

6. Projected AC Bed Requirements: The number of $\mathrm{AC}$ beds required each day is the sum of the number of COVID-19+ and COVID-19- AC patients.

7. Ventilator Requirements: The number of ventilators required is estimated as the sum of $50 \%$ of nonCOVID-19 IC patients and 100\% of COVID-19+ IC patients. 
The model is implemented in R 3.5, RStudio, RShiny 1.4.0 and Python 3.7. The parameters used may be modified as data become available, for use at other institutions, and to generate sensitivity analyses.

We illustrate the use of the model by estimating the demand generated by COVID-19+ arrivals for a hypothetical acute care medical center with 100 IC beds, 220 AC beds, 75 ventilators, $80 \%$ occupancy of both IC and AC beds, 1 COVID-19+ IC patient, 2 COVID-19+ AC patients, and a total patient doubling time of 6 days. For COVID-19+ patients, $70 \%$ were assumed to stay only in AC for an average LOS of 5 days and $30 \%$ were assumed to spend at least one day in IC with an average IC LOS of 8 days and average AC LOS of 9 days (Table 1).

\section{Model projections}

The model calculated that the number of patients requiring an IC bed would equal the number of IC beds on Day 23 (Figure 1a), the number of patients requiring a ventilator would equal the number of ventilators available on Day 27 (Figure 1a), and the number of patients requiring an $\mathrm{AC}$ bed and coverage by the Medicine Service would equal the capacity of the Medicine service on Day 21 (Figure 1b).

\section{Sensitivity analyses}

When the doubling time of new admissions is decreased to 3 days (50\%), the number of days until IC and AC hit capacity decrease are, respectively, 11 and 9 . When the doubling time is increased to 12 days (200\%), the number of days until IC and AC hit capacity are, respectively, 51 and 51.

\section{Discussion:}

In response to the COVID-19 epidemic, hospitals must understand their current and future capacity to care for patients with severe illness. While there is significant uncertainty around the parameters used to develop this model, the analysis is based on transparent logic and starts from observed data to provide a robust basis of projections for hospital managers. The model demonstrates the need to address critical questions about staffing patterns for IC and $\mathrm{AC}$, and equipment capacity such as ventilators.

An insight revealed by the model is that under some plausible scenarios, AC may reach capacity before IC and become a bottleneck preventing discharges from IC. In addition to increasing capacity, managers must develop strategies to reduce $\mathrm{AC}$ occupancy such as accelerating efforts to discharge patients to convalescent or step-down care such as a hotel or nursing care facility.

The main limitation of this model is the fact that most of the inputs are based on estimates. The epidemiology of COVID-19 is critically important, and ongoing research will update the model. The model is very sensitive to specific aspects of the epidemiology, especially doubling time. The model environment can be easily updated with new parameter data to generate a more precise projection.

Table 1: Patient Cohorts and Length of Stay Estimates

\begin{tabular}{|c|l|c|c|c|c|c|}
\hline \multicolumn{2}{|c|}{ COVID Patient Cohorts } & \multicolumn{3}{c|}{ LOS Estimates in Model } \\
\hline Index & Path & Fraction of Patients (\%) & LOS Floor & LOS ICU & LOS Floor & Total LOS \\
\hline 1 & Floor & 70.4 & 5 & & 5 \\
\hline 2 & Floor -> ICU -> Floor & 13.0 & 4 & 9 & 4 & 17 \\
\hline 3 & Floor -> ICU & 1.8 & 6 & 9 & 15 \\
\hline 4 & ICU -> Floor & 13.0 & & 9 & 4 & 13 \\
\hline 5 & ICU & 1.8 & & 11 & 11 \\
\hline
\end{tabular}


medRxiv preprint doi: https://doi.org/10.1101/2020.03.24.20042762; this version posted March 26, 2020. The copyright holder for this preprint (which was not certified by peer review) is the author/funder, who has granted medRxiv a license to display the preprint in perpetuity.

Figure 1: Projected Total ICU and General Medicine Team Acute Care Census
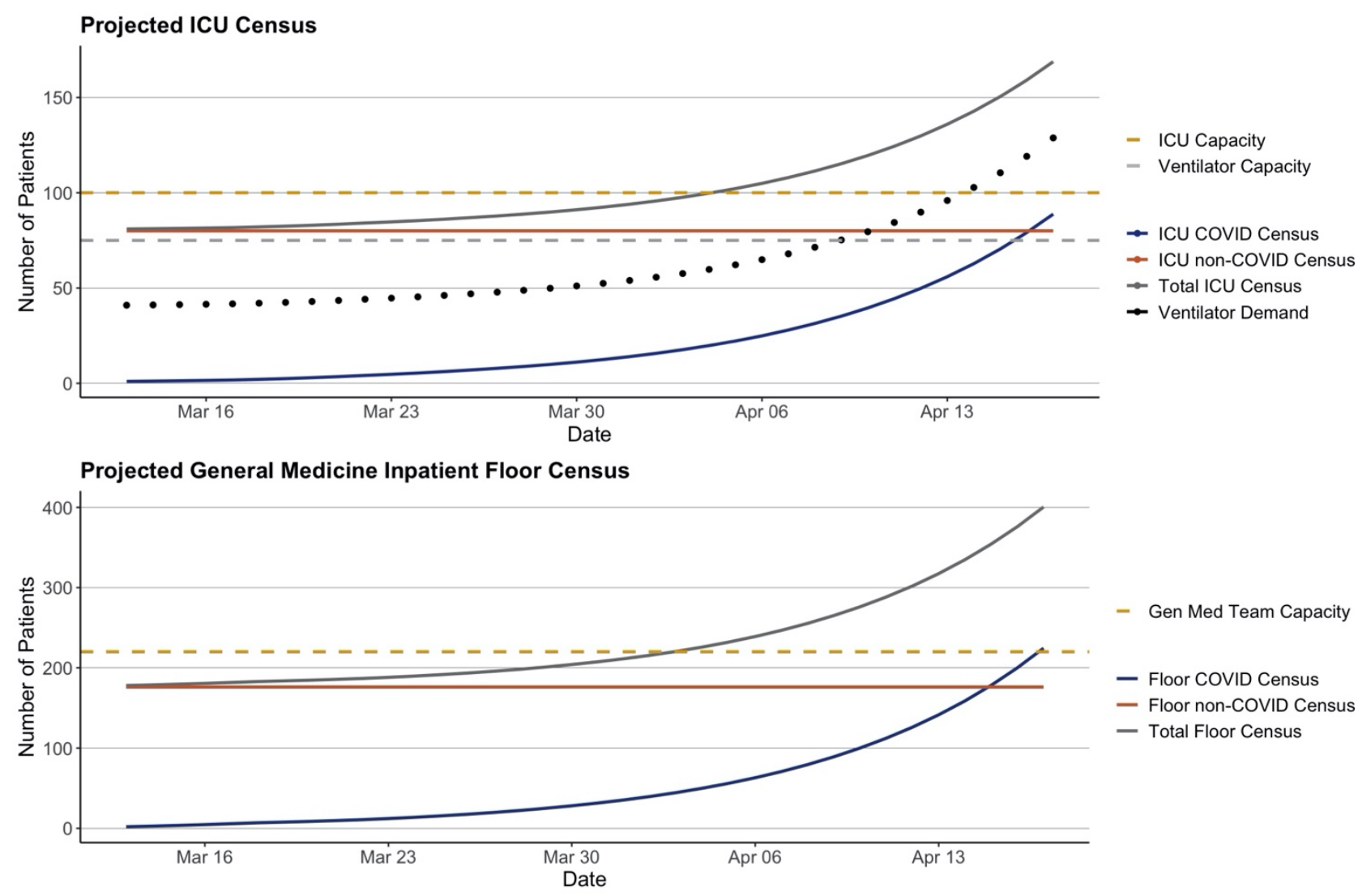

\section{Author Statement}

The authors have no sources of funding nor conflicts or other disclosures. Teng Zhang, Kelly McFarlane, and Jacqueline Vallon have reviewed all of the data and analyses and take responsibility for their accuracy. Teng Zhang, Kelly McFarlane, Jacqueline Vallon, Linying Yang, and Jin Xie built the model. Jose Blanchet, Peter Glynn, Kristan Staudenmayer, Kevin Schulman, and David Scheinker led the conceptualization and design of the model. Teng Zhang, Kelly McFarlane, Kevin Schulman, and David Scheinker led drafting the correspondence. All authors contributed to critical reading and revision of the correspondence.

This is a mathematical model with no human subjects data. 
medRxiv preprint doi: https://doi.org/10.1101/2020.03.24.20042762; this version posted March 26, 2020. The copyright holder for this preprint (which was not certified by peer review) is the author/funder, who has granted medRxiv a license to display the preprint in perpetuity.

It is made available under a CC-BY-NC-ND 4.0 International license .

\section{References}

1. Dong E, Du H, Gardner L. An interactive web-based dashboard to track COVID-19 in real time. The Lancet Infectious Diseases. Published online February 19, 2020. doi:10.1016/S1473-3099(20)30120-1

2. World Health Organization. Coronavirus disease 2019 (COVID-19) Situation Report - 51. World Health Organization. https://www.who.int/docs/default-source/coronaviruse/situation-reports/20200311-sitrep-51-covid19.pdf?sfvrsn=1ba62e57_10. Published March 11, 2020. Accessed March 16, 2020.

3. White House. Proclamation on Declaring a National Emergency Concerning the Novel Coronavirus Disease (COVID-19) Outbreak. White House. https://www.whitehouse.gov/presidential-actions/proclamation-declaringnational-emergency-concerning-novel-coronavirus-disease-covid-19-outbreak/. Published March 13, 2020. Accessed March 16, 2020.

4. Wu Z, McGoogan JM. Characteristics of and Important Lessons from the Coronavirus Disease 2019 (COVID-19) Outbreak in China: Summary of a Report of 72314 Cases From the Chinese Center for Disease Control and Prevention. JAMA. Published online February 24, 2020. doi:10.1001/jama.2020.2648

5. Grasselli G, Pesenti A, Cecconi M. Critical Care Utilization for the COVID-19 Outbreak in Lombardy, Italy: Early Experience and Forecast During an Emergency Response. JAMA. Published online March 13, 2020. doi:10.1001/jama.2020.4031

6. SURF Stanford Medicine, Stanford University. COVID-19 Hospital ICU and Floor Census Model. https://surf.stanford.edu/covid-19-tools/covid-19-hospital-projections/ (Accessed March 23, 2020)

7. Zhou, Fei, et al. Clinical course and risk factors for mortality of adult inpatients with COVID-19 in Wuhan, China: a retrospective cohort study. The Lancet. Published online March 11, 2020.

doi:https://doi.org/10.1016/S0140-6736(20)30566-3

8. Guan, Wei-jie, et al. Clinical characteristics of coronavirus disease 2019 in China. New England Journal of Medicine. Published online February 28, 2020. doi:10.1056/NEJMoa2002032 